\title{
Economic Feasibility Analysis of Garbage Separation and Recovery Mode in Family and Residential Areas
}

\author{
Zhiqiong Zou, Wei Xiong \\ Department of Materials Science, Jingchu Institute of Technology, Jingmen, Hubei, 448000
}

Keywords: family and community; garbage sorting and recycling mode; economic feasibility

\begin{abstract}
China has not been standardized and implemented in the field of garbage separation and recovery, which leads to a lot of waste of sustainable use and recycling of resources, most of which are derived from the garbage produced by families and communities. Therefore, the establishment of garbage separation and recovery mode within the scope of family and residential areas will help our country to popularize domestic waste sorting and recycling in cities. Through the understanding of the important significance of the garbage sorting and recycling model of family and community, this paper analyzes the economic and national economic benefits of enterprises from many angles, and finds out the feasible countermeasures to help the development of the garbage sorting and recycling in China.
\end{abstract}

\section{Introduction}

Garbage sorting and recycling mode has been planned and implemented in some developed countries as early as possible, and has achieved good results. It has become the habit of residents in Japan and Germany to divide domestic waste into combustible and non combustible or degradable and non degradable species. In developed countries, people not only have the basic sense of garbage sorting, but also use specified containers to install rubbish. At the same time, developed countries will set up corresponding garbage collection departments, and specialized personnel will guide residents to reuse and collect garbage. For example, materials such as glass, paper and plastic can be recycled by full government power, and the amount of recovery is more than half of its production. In the garbage collection recycling model of many family and residential areas, the amount of the source reduction, the change of the recycling price and the roadside recycling are mostly changed.

\section{The Significance of Garbage Separation and Recovery Mode in Family and Residential Areas.}

Most of the household garbage disposal methods in our country are unified recycling and landfill. There is no classification of garbage in the setting of the garbage bin, but it is only rough treatment of garbage, which leads to the waste of many recyclable resources. Because of the vast population of our country, there are no strict laws and regulations to regulate the treatment of household garbage, and many garbage collection and recycling programs are only in the process of publicity and promotion, although the waste purchase station and garbage cleaning personnel can be to some extent to the garbage. Classification recovery, but can not form a corresponding awareness of the residents, relying only on the public opinion and willingness to classify the garbage, and no scientific and reasonable recycling.The collection and recycling model of household and community in foreign countries has formed a management system with economic benefits. Through the propaganda and training of the government, the public has a strong concept of garbage segmentation, and it can increase the income of the government and the economic benefit of the civil enterprises through this garbage collection model. And improve the quality of life of the residents. This multifaceted economic behavior is highly praised by the public. Therefore, the government should also link the garbage collection and recycling with the living quality of people's living and the quality of life, let the residents realize the benefits of the garbage classification to life, 
and drive the residents and enterprises to recycle the garbage by government means, so that the model of garbage collection and return is good in the family and community. Ethos can generate enormous social and environmental benefits and economic benefits, and enhance the economic feasibility of its implementation[1].

\section{Feasibility Analysis of Garbage Separation and Recovery Mode in Family and Residential Areas}

The existing household and residential garbage collection and recovery models in China are divided into two modes: wet refuse and dry refuse. The recovery mode of wet garbage begins with the comminution of garbage. The wet waste is centrifuged with special equipment. The waste water is discharged into the sewer, and the residue is treated as residual garbage. The recycling mode of dry garbage is divided into returnable and non recyclable by sorting the garbage manually, and then the garbage can be returned. The refuse collected is handed over to the garbage collection department for disposal, and the unrecyclable refuse is uniformly buried or burned.

According to the survey on the taxonomy of household garbage collection and recycling in some communities, it is found that most of the residents are willing to participate in the garbage collection activities of the classified model. Although the cognition of the classification of dry and wet two types of garbage is not enough, more than $80 \%$ of the residents are willing to receive the education of the garbage classification knowledge. Willing to actively participate in the activities, the vast majority of the residents want to get some material rewards or lifestyle compensation, this form can improve the participation of residents and the willingness to classify garbage[2].

The residents are more willing to make a rough classification of domestic waste in the household garbage collection classification, roughly judge the dry and wet properties of the garbage, and the subsequent subdivision category is completed by the related garbage collection enterprises. Many residents want the government to provide some high-tech products on garbage disposal for the daily classification of garbage, for example, using special tools to screen out recyclable wastes such as plastics, paper products and metals in garbage. Residents hope to use these small and widely used equipment for daily garbage sorting, so as to reduce the process of subdivision. This can meet the hardware requirements of fine classification in the community. Our government should support and satisfy it from a technical level.

According to the results of the practice survey, the household garbage collection and recycling model of a residential residential district is carried out for a residential district with high resident occupancy rate and complete community facilities. After five years, the garbage collection enterprise in charge of the district has been losing money, but the national economic benefit has been increasing. The garbage sorting and recycling under this mode has reduced the economic benefits of enterprises, but brought huge invisible social benefits. If the part of the national economic income is transferred to the enterprise, it can not only make reasonable use of the government financial funds, but also make up the part of the loss of the enterprise, support the development of the related enterprises with the national policy, and introduce the relevant laws and regulations as the guarantee of increasing the implementation. The model is fully sustainable.

\section{Economic Benefit Analysis of Garbage Separation and Recovery Mode in Family and Residential Areas}

With the continuous improvement of the process of socialist modernization, the garbage produced in the small and medium-sized cities of our country is increasing. In this case, China's special "China Environmental Assessment Report" has analyzed the situation of domestic waste. According to the statistics of the total amount of garbage produced in a week, the living garbage in this district is increasing rapidly with the rate of more than $10 \%$ per year, and the total amount of dry garbage is about $1 / 3$ of the wet garbage[3].

The economic benefit produced by recyclable garbage is great. Taking the recovery price of the recyclable garbage of a single district as an analysis, in a week, the paper waste produced by the 
district can obtain nearly 140 thousand yuan of income, nearly 170 thousand yuan of plastic waste, nearly 30 thousand yuan of metal type waste, and nearly 150 thousand yuan of glass type refuse, which can recover the total garbage total. The total amount is about 500 thousand yuan. Through advanced science and technology, the cost of garbage sorting and transportation can be greatly reduced. By dewatering the wet waste through the equipment, nearly $90 \%$ of the water content can be removed, and the volume and weight of the garbage can be reduced; the dry garbage can be sorted manually or by machine, and the transportation weight can be reduced. In the first tier cities, the transportation and disposal cost of garbage in transportation is 80 yuan / ton, and the cost of compressing and recycling at the garbage disposal station is 70 yuan / ton. The subsequent treatment of garbage classification is mainly through the dewatering and compression treatment of wet refuse, simplifying the composition of garbage, so as to save costs. Therefore, household and residential garbage classification and recycling mode can reduce the government's expenditure on garbage disposal.

At the same time, the garbage collection and recycling need to be equipped with special garbage cans. In order to make the residents classify the dry and wet garbage, the government must purchase a large number of professional forms of garbage cans and put them in the community. The cost of the garbage collection and the maintenance and repurchase of the garbage cans is roughly a few thousand yuan each year. At the same time, the community also needs the auxiliary cleaning and garbage sorting personnel to provide auxiliary work for the classification of residents' garbage, so the artificial expenditure is also a government expenditure. At the same time, the interior of the community should be equipped with corresponding domestic waste disposal equipment. The average market price of modern equipment is about eighty thousand yuan, the year of use is five years, and the annual depreciation expense and the cost of electricity and electricity are added to the garbage disposal equipment. After the calculation, the national economic benefit of the dry and wet classification treatment of domestic waste is positive. Value, can produce a certain income[4].

\section{The Intangible Benefits for the Nation}

From the above analysis, we can find that the family residential residential garbage collection recycling model can produce huge economic benefits, but we can not ignore the improvement of the model for the quality of life of residents, and then produce enormous intangible benefits in the social scope. The classification of domestic garbage can not only reduce the total amount of garbage, reduce the transportation weight of garbage and reduce the cost of transportation, but also reduce the amount of incineration of garbage in the treatment plant, and then open up a new way to protect the natural environment. At the same time, garbage classification and recycling based on advanced science and technology and equipment can improve the efficiency of garbage disposal, reduce unnecessary resource consumption, lead people into the new era of low carbon life, and create a healthy living environment for the residents. Therefore, family residential garbage classification and recycling mode has a subtle improvement on China's humanities and environment[5].

Through the assessment and analysis of the national economic benefits under the household garbage collection recycling model, the government can guide the government to improve the national economic efficiency in a short time and reduce the state financial expenditure if the garbage classification model is removed in the community. While producing additional economic benefits, the government can allocate this part of the financial revenue to the construction of the infrastructure for the recycling of garbage in the community. At the same time, the government can fully support the enterprises and institutions related to garbage collection, transfer the economic benefits to the implementation of the classification projects, and encourage the enterprises and residents to devote themselves to the garbage. In the construction of classification.

\section{The Economic Benefits for Enterprises}

The purpose of the enterprises engaged in garbage collection is to profit, and the household and residential garbage collection and recycling model can reduce the cost and the disposal cost of the 
garbage transportation for the enterprise. If the government can propagate and guide the residents to carry out the classification of garbage independently, the enterprises can transport and deal with the classified garbage directly in the case of saving manpower and resources. Establishing the basic order and awareness of garbage classification within the district can better improve the profitability of enterprises. The enterprises can sell the classified waste directly, or process the waste by compressed or extracted material. This kind of garbage collection mode can not only reduce the amount of garbage transportation, but also the cost of transportation and treatment, and form a benign circular development model in the industrial chain of garbage collection.

In the community, the enterprises that classify the living garbage are mainly the property companies of the community, and the total income of the property company is derived from the property fee of the owner, and some of these property fees are put into the disposal of the garbage. In the household garbage collection recycling model, the enterprise can recycle the living garbage and make use of the valuable part, and then produce the extra economic profit. So the property companies of the community only need a one-time investment in the classification mode of domestic garbage, and invest in the purchase of trash cans, the wages of the cleaning personnel and the maintenance of the garbage disposal equipment. Under the completed residential garbage collection mechanism, the enterprises can obtain the sanitation fee and the recyclable garbage by the residents. The re sale aspect expands the extra income of the enterprise.

The enterprise needs to consider the separation of dry and wet garbage and extract the valuable and recyclable part in the treatment of daily living garbage, so it is necessary for the enterprise to provide the professional garbage separation equipment and the related personnel.

In the general community, the enterprise needs to be equipped with roughly 5-7 people engaged in garbage sorting and cleaning. The basic salary of each employee is 1500-2000 yuan per month, and the purchase cost of the equipment is 800 thousand yuan, which does not include the maintenance of equipment and the annual depreciation expense. At the same time, the enterprises also need to be equipped with professional garbage sorting personnel, daily guidance to the residents of the community and the classification of garbage, and related personnel to operate the professional equipment. These personnel and expenditures have a little improvement in the traditional residential property garbage disposal mode[6].

According to the analysis of the above data, we can know that the expenditure of the residential property enterprises in the household waste classification recycling mode is greater than that of the income. If the enterprises deal with wet refuse and centrifugation and drying, enterprises will lose more. Moreover, in the early stage of residents' garbage sorting consciousness, the actual garbage disposal process of residential property enterprises will be more complex and difficult than theory. Ben. Therefore, in the community, the household and residential garbage collection and recycling mode should not be taken alone by the enterprise alone, and the funds and resources of the government must be the backing force. The policy should make up for the loss of the enterprise through the form of appropriation and assistance, so that more enterprises will be willing to participate in the reform of the garbage classification treatment and take this task as a far-reaching strategic goal of sustainable development.

\section{Conclusion}

The taxonomy of household garbage collection and recycling is of great significance to the residents and communities in China. This kind of garbage collection model has a certain feasibility in the national economic benefit and the willingness of the residents to participate. Although the relevant enterprises engaged in garbage clearance will have a certain loss, if the government extracts some of the economic benefits obtained from the gains to support the development of private enterprises and the implementation of the corresponding regulations and policies, we should vigorously promote the advantages of garbage collection and recycling and encourage enterprises and residents to participate in the project. Household and residential garbage classification and recovery mode will get better and faster development. 


\section{Acknowledgment}

Jingchu institute of technology school-level scientific research project (youth project) QN 201608 Feasibility study on waste classification in Jingmen city

\section{References}

[1] Al-Mahrouqi J, Falcone G. An Expanded Matrix to Scope the Technical and Economic Feasibility of Waste Heat Recovery from Mature Hydrocarbon Fields[C]// Stanford Geothermal Workshop. 2016.

[2] Hussain M N, Samad T A, Janajreh I. Economic Feasibility of Biodiesel Production From Waste Cooking Oil in the UAE[J]. Sustainable Cities \& Society, 2016, 26:217-226.

[3] Xiong J, Ng T S A, Wang S. An optimization model for economic feasibility analysis and design of decentralized waste-to-energy systems [J]. Energy, 2016, 101:239-251.

[4] Zhang H, Wen Z, Chen Y. Environment and economic feasibility of municipal solid waste central sorting strategy: a case study in Beijing [J]. Frontiers of Environmental Science \& Engineering, 2016, 10(4):10.

[5] García P E E, Cortés M E T, Gómez R J S, et al. Economic feasibility analysis for electrical generation from biogas in waste disposal sites in Mexico City[J]. Applied Economics, 2017, 48(59):1-11.

[6] Alvarez R E A, Roman M B, Kirk D, et al. Technical and economic feasibility of a solar-bio-powered waste utilization and treatment system in Central America[J]. Journal of Environmental Management, 2016, 184(Pt 2):371-379. 